\title{
Association of Fat Mass and Obesity-associated Gene (FTO) rs9939609 Variant with Early Onset Obesity among Bataknese and Chinese Children in Indonesia: A Case-control Study
}

\author{
Siska Mayasari Lubis ${ }^{1, *}$, Miswar Fattah ${ }^{2}$, Harun Alrasyid Damanik ${ }^{3}$, Jose Rizal Latief Batubara ${ }^{4}$ \\ ${ }^{1}$ Pediatric Endocrinology Division, Child Health Department, Faculty of Medicine, University of Sumatera Utara, H. Adam Malik General Hospital, \\ Jl. Dr. Mansyur No. 9 Kampus USU, Medan, Indonesia \\ ${ }^{2}$ Department of Molecular Biology, Prodia Clinical Laboratory, Jl. Kramat Raya No.150, Jakarta, Indonesia \\ ${ }^{3}$ Department of Nutritional Sciences, Faculty of Medicine, University of Sumatera Utara, Jl. Dr. Mansyur No. 9 Kampus USU, Medan, Indonesia \\ ${ }^{4}$ Pediatric Endocrinology Division, Child Health Department, Faculty of Medicine, University of Indonesia, Cipto Mangunkusumo General Hospital, \\ Jl. Salemba Raya No.6, Jakarta, Indonesia. \\ *Corresponding author. E-mail: dr_siskalubis@yahoo.com
}

Received date: Mar 11, 2017; Revised date: Jun 4 2017; Accepted date: Jun 5, 2017

\section{Abstract}

$\mathrm{B}$ ACKGROUND: Childhood obesity is associated with the risk of adult obesity and obesity-related chronic disease. The fat mass and obesity-associated gene (FTO) rs9939609 variant are of particular interest because of its association with body mass index (BMI) and obesity-related phenotypes. This study was conducted to investigate the association between FTO gene rs9939609 variant with early onset obesity among Bataknese and Chinese children in Medan, Sumatera Utara, Indonesia.

METHODS: The case-control study was carried out at 10 elementary schools in Medan. There were 212 children recruited; 56 early onset obesity and 61 control Bataknese and 49 early onset obesity and 46 control Chinese children. This study included a questionnaire, anthropometric measurements, and blood test analysis. rs9939609 polymorphism genotyping was performed using RT-PCR. Logistic regression, odds ratio (OR) and 95\% confidence interval (CI) were calculated to determine the risk of obesity associated with the risk alleles, $p<0.05$ was considered as statistically significant.

RESULTS: This study found a significant association between rs9939609 and early onset obesity in Chinese children $(p=0.01)$, but not in Bataknese. The frequency of AA genotype was lower in the early onset obesity than in the normal weight children, while an OR of 0.69 showed that this genotype may protect against weight gaining and that the TT genotype may predispose to obesity.

CONCLUSION: We concluded that the FTO gene rs9939609 is associated with early onset obesity in Chinese ethnicity but not in Bataknese.

KEYWORDS: pediatric obesity, FTO gene, rs9939609, polymorphism, Indonesia

Indones Biomed J. 2017; 9(3): 147-52

\section{Introduction}

Obesity is a consequence of unhealthy lifestyle combined with genetic susceptibility, requires attention due to the burden placed on the health care system for children and adults.(1-3) Childhood obesity poses a serious challenge to society because it is associated with the risk of adult obesity and obesity-related chronic diseases such as type 2 diabetes mellitus (T2DM) and cardiovascular disease.(4-6)

Interactions between genetic and environmental factors determined individual susceptibility to obesity. $(4,5)$ The level of genetic factors involvement on obesity is estimated to be $40-60 \%$.(2) Genes related to obesity have 
frequently been in favor.(2,7) Several genome-wide related studies had reported the association between the fat mass and obesity-associated (FTO) gene with obesity.(6,7) Single nucleotide polymorphisms (SNPs) in the FTO gene are correlated with the increased body mass index (BMI), as previous studies have reported.(7-9)

FTO gene is highly expressed in the arcuate hypothalamus and regulated by fasting/feeding cycles, the FTO protein possessed an important regulatory role in maintaining energy balance.(10) Variations in the FTO gene strongly contribute to the development of early-onset obesity. The A-allele of the variant rs 9939609 is associated with a $31 \%$ increasing the risk of developing obesity, revealing the fact that FTO rs9939609 variant is associated with an increased risk for both T2DM and obesity. $(9,11)$ Regarding the European population, the A-allele of the rs9939609 variant has been reported has the strongest effects, however, it is different from the population in Asia, A-allele was less found in predisposing obesity, so that the effect of the rs9939609 variant becomes weaker.(9)

Several studies have shown that the FTO rs9939609 is strongly associated with BMI and the risk of obesity,(12-17) but the association was varied in different ethnicities.(18) The mechanism responsible for its influence on the development of obesity remains to be explained.(2) We have investigated the association between the FTO rs9939609 variant with early onset obesity among Bataknese and Chinese children in Indonesia.

\section{Methods}

A case-control study was conducted in 10 elementary schools in Medan, Sumatera Utara, Indonesia. Case and control groups were Bataknese and Chinese children with early onset obesity and normal weight children; 56 early onset obesity and 61 control Bataknese, and 49 early onset obesity and 46 control Chinese children, aged 6-12 years. The study included a questionnaire for parents or guardians, anthropometric measurements, and blood test analysis from the children. The questionnaires requested information on parents' and children's ethnicity, the onset of obesity, date of birth, and family history of obesity. Early onset obesity was defined as obesity onset before the age of 6 years in children.(10) Ethnicity and family history of obesity were derived from three-generation pedigrees.(19)

Children were under steroid treatment, had chronic infection or disease, endocrine disorder, genetic disease, or short stature were excluded from this study. This study was approved by The Ethics Committee of The Faculty of Medicine, University of Sumatera Utara, Medan, Indonesia, with ethical number 343/KOMET/FK USU/2013. All children and parents gave written informed consent that clearly stated that blood samples would be used for scientific research purposes, including genetic studies.

\section{Anthropometry Measurements}

Anthropometric measurements included body weight (in $\mathrm{kg}$ ), was measured to the nearest $0.1 \mathrm{~kg}$ by digital machine. Height (in $\mathrm{cm}$ ) was measured to the nearest 0.1 $\mathrm{cm}$ by using stadiometer. All instruments were validated following the manufacturer's protocol. Waist circumference (in $\mathrm{cm}$ ) was determined at the midpoint between the iliac crest and lowermost margin of the ribs by non-stretchable measuring tape while the child was in a standing position and after expiration. BMI was calculated as weight $(\mathrm{kg}) /$ height $\left(\right.$ meter $\left.^{2}\right) .(20)$ Children who had a BMI of more than $95^{\text {th }}$ Percentile (P95) based on age and gender specific BMI Centers for Disease Control and Prevention (CDC) standards 2000 were considered obese, and those who had a BMI of $3^{\text {rd }}$ percentile (P3) to $85^{\text {th }}$ percentile $(\mathrm{P} 85)$, by the same standards, were considered to have normal weight.

\section{Laboratory Assessment}

A whole blood ethylenediaminetetraacetic acid (EDTA) sample was collected from each child for genetic studies. The genomic DNA was extracted using the high pure template preparation kit (Roche Diagnostics GmbH, Mannheim, Germany). Genotyping was performed using a TaqMan assay for rs9939609 polymorphism (Assay ID C 25638153 10; Applied Biosystems, Foster City, CA). Real-time PCR was performed in $25-\mu \mathrm{L}$ reactions containing $12.5 \mu \mathrm{L}$ TaqMan Genotyping Master Mix, $1.25 \mu \mathrm{L}$ TaqMan genotyping assay mix (20X) include primer and probe, 11.25 $\mu \mathrm{L}$ DNase-free, RNase-free water and approximately $20 \mathrm{ng}$ of template DNA in $5 \mu \mathrm{L}$ Thermal cycling was run on a Biorad CFX96 (Biorad, München, Germany) using the following conditions: $95^{\circ} \mathrm{C}$ for 10 minutes and 40 cycles of $95^{\circ} \mathrm{C}$ for 15 seconds and $60^{\circ} \mathrm{C}$ for 90 seconds. SNP genotyping was performed with allelic discrimination method using CFX96TM Real-Time PCR software (Biorad, Munchen, Germany).

To verify the results of genotyping, a selection of three genotype (AA, AT, and TT) samples was regenotyped with $100 \%$ concordance by sequencing by the Sanger's dideoxy chain termination reaction using Big-Dye Terminator v.1.1 Cycle Sequencing Kit (Applied Biosystems, Foster City, USA) and the ABI 3500 sequencer (Applied Biosystems, 
Foster City, USA), using oligonucleotides 5'-AAGAGAT GATCTCAAATCTACTTTATGAGATA-3' (forward) and 5'-AGGATAGTTTCGATCTATTGACCTC-3' (reverse) (IDT DNA, Singapore).

\section{Statistical Analysis}

Data were analyzed using SPSS software version 24 (SPSS Inc., Chicago, IL, USA). Quantitative variables were expressed as mean \pm standard deviation (SD). The descriptive statistics were used to analyze sociodemographic characteristics of the subjects. Anthropometric measurements between case and control were compared using student's t-test. We examined the associations between genotype and allele with obesity by using logistic regression analysis (enter method), odds ratio (OR) and 95\% confidence interval (CI) were calculated to determine the risk of obesity associated with the risk alleles. Allele frequencies were also analyzed separately by Pearson's chisquare test based on case and control groups and ethnicity. Hardy-Weinberg Equilibrium test (HWE) was applied to determine the variation in the distribution of alleles and genotypes within the concerned population, was analyzed using Pearson chi-squared test, $p<0.05$ was considered as statistically significant.

\section{Results}

Characteristics of children in this study are given in Table 1. Children in the case group had significantly higher levels of BMI, waist circumference, and body weight. There was significant association between body weight, height, BMI, waist circumference, and family history of obesity with nutritional status, $p<0.05$.

In our study, the genotypes of the rs9939609 variant were in Hardy-Weinberg equilibrium $(p=0.26)$ in both early onset obesity and control groups. The frequency of AA genotypes was higher in the control group than in the early onset obesity groups, but no significant difference was observed between genotypes rs9939609 and early onset obesity $(p=0.52,95 \% \mathrm{CI}=0.23-2.11)$ and $\mathrm{OR}=0.69$ for AA compared to TT genotypes. There was a significant difference between genotypes of rs9939609 in Chinese children, $p=0.01$, but not in Bataknese children, but AA genotypes in Bataknese children increased the risk of obesity among subjects $(\mathrm{OR}=2.43)$ (Table 2$)$.

There was a significant association between genotypes AA/AT and early onset obesity in Chinese children ( $p=0.04$, $\mathrm{OR}=0.39,95 \% \mathrm{CI}=0.16-0.99)$. There was no significant
Table 1. Characteristics of subjects.

\begin{tabular}{lccc}
\hline & Case & Control & $p$ \\
\hline Age (years) & $9.87 \pm 1.49$ & $9.17 \pm 1.62$ & 0.01 \\
Gender & & & \\
$\quad$ Male & $67(63.8)$ & $64(59.8)$ & 0.55 \\
$\quad$ Female & $38(36.2)$ & $43(40.2)$ & \\
Body weight (kg) & $46.60 \pm 10.44$ & $27.90 \pm 5.81$ & 0.01 \\
Body height (cm) & $136.50 \pm 9.90$ & $130.68 \pm 9.86$ & 0.01 \\
BMI (kg/m $\left.{ }^{2}\right)$ & $24.73 \pm 2.96$ & $16.15 \pm 1.48$ & 0.01 \\
Waist circumference (cm) & $76.39 \pm 8.83$ & $57.76 \pm 6.96$ & 0.01 \\
Ethnic & & & \\
$\quad$ Bataknese & $56(53.3)$ & $61(57.0)$ & 0.6 \\
$\quad$ Chinese & $49(46.7)$ & $46(43.0)$ & \\
Family history of obesity & & & \\
$\quad$ Yes & $72(34.0)$ & $26(12.3)$ & 0.01 \\
$\quad$ No & $33(15.6)$ & $81(38.2)$ & \\
\hline Dat a & & & \\
\hline
\end{tabular}

Data are means $\pm \mathrm{SD}$, or percentages. BMI: Body mass index. Associations are considered significant when $p<0.05$.

association between genotypes and early onset obesity in Bataknese children $(p=0,53, \mathrm{OR}=1,26,95 \% \mathrm{CI}=0.61-2.61)$ (Table 3).

\section{Discussion}

The association of FTO gene rs9939609 variant with obesity has been replicated in different European populations. $(13,21-25)$ However, it was inconsistent in populations of non-European ancestry.(23) A previous longitudinal study reported FTO genetic effects do not effected early onset obesity before the age of 7 years (26), this result in accordance with our study, but, in this study we found a significant association between rs9939609 FTO gene with early onset obesity in Chinese children, and this result is in agreement with several studies in other Asian populations. $(1,23,24,27)$. The geographic discrepancies may be due to the children's lifestyle, diet, and physical activity, age, or other regional differences, suggesting the need for more studies in different populations for better recognition of the role of FTO gene in obesity.

This study is the first study examining the prevalence of the rs9939609 FTO gene and its association with early onset obesity in Bataknese and Chinese ethnic in Indonesia population. Our finding of a significant association between rs9939609 polymorphisms in Chinese children, concurs 
Table 2. Obesity status, ethnicity, and FTO rs9939609 genotypes of subjects.

\begin{tabular}{|c|c|c|c|c|c|c|c|}
\hline & \multirow{2}{*}{ Genotypes } & \multicolumn{2}{|c|}{ Case } & \multicolumn{2}{|c|}{ Control } & \multirow{2}{*}{ OR (95\% CI) } & \multirow{2}{*}{$p$} \\
\hline & & n & $\%$ & n & $\%$ & & \\
\hline \multirow[t]{3}{*}{ Total } & AA & 6 & $5.70 \%$ & 8 & $7.50 \%$ & $0.69(0.23-2.11)$ & 0.52 \\
\hline & $\mathrm{AT}$ & 32 & $30.50 \%$ & 37 & $34.60 \%$ & $0.80(0.45-1.44)$ & 0.46 \\
\hline & $\mathrm{TT}^{1}$ & 67 & $63.80 \%$ & 62 & $57.90 \%$ & 1.00 & \\
\hline \multirow[t]{3}{*}{ Bataknese } & $\mathrm{AA}$ & 6 & $10.70 \%$ & 3 & $4.90 \%$ & $2.43(0.56-10.6)$ & 0.19 \\
\hline & AT & 22 & $39.30 \%$ & 24 & $39.30 \%$ & $1.11(0.52-2.4)$ & 0.79 \\
\hline & $\mathrm{TT}^{1}$ & 28 & $50.00 \%$ & 34 & $55.70 \%$ & 1.00 & \\
\hline \multirow[t]{3}{*}{ Chinese } & AA & 0 & $0.00 \%$ & 5 & $10.90 \%$ & $0.00(0.00)$ & 0.01 \\
\hline & AT & 10 & $20.40 \%$ & 13 & $28.30 \%$ & $0.55(0.21-1.44)$ & 0.22 \\
\hline & $\mathrm{TT}^{1}$ & 39 & $79.60 \%$ & 28 & $60.90 \%$ & 1.00 & \\
\hline
\end{tabular}

Logistic regression analysis was adjusted for sex, age. OR: Odds ratio; CI: Confidence interval. ${ }^{1}$ Carriers with the TT genotype are used as the reference group. Associations are considered significant when $p<0.05$.

Table 3. Obesity status and ethnicity according to AA/AT and TT genotypes.

\begin{tabular}{|c|c|c|c|c|c|c|c|}
\hline & \multirow{2}{*}{ Genotypes } & \multicolumn{2}{|c|}{ Case } & \multicolumn{2}{|c|}{ Control } & \multirow{2}{*}{ OR $(95 \%$ CI) } & \multirow{2}{*}{$p$} \\
\hline & & n & $\%$ & $\mathbf{n}$ & $\%$ & & \\
\hline \multirow[t]{2}{*}{ Total } & $\mathrm{AA} / \mathrm{AT}$ & 38 & $36.20 \%$ & 45 & $42.10 \%$ & $0.78(0.45-1.36)$ & 0.38 \\
\hline & $\mathrm{TT}^{1}$ & 67 & $63.80 \%$ & 62 & $57.90 \%$ & & \\
\hline \multirow[t]{2}{*}{ Bataknese } & $\mathrm{AA} / \mathrm{AT}$ & 28 & $50.00 \%$ & 27 & $44.30 \%$ & $1.26(0.61-2.61)$ & 0.53 \\
\hline & $\mathrm{TT}^{1}$ & 28 & $50.00 \%$ & 34 & $55.70 \%$ & & \\
\hline \multirow[t]{2}{*}{ Chinese } & $\mathrm{AA} / \mathrm{AT}$ & 10 & $20.40 \%$ & 18 & $39.10 \%$ & $0.39(0.16-0.99)$ & 0.04 \\
\hline & $\mathrm{TT}^{1}$ & 39 & $79.60 \%$ & 28 & $60.90 \%$ & & \\
\hline
\end{tabular}

Logistic regression analys is was adjusted for sex, age. OR: Odds ratio; CI: Confidence interval. ${ }^{1}$ Carriers with the TT genotype are used as the reference group. Associations are considered significant when $p<0.05$.

with results in Chinese children in other countries. $(4,12,28)$ Although we did not find AA genotype in case group in Chinese population, but in Control group we found 10.5\% subject with AA genotype. It can be argued that Chinese population in our country maybe has similarity with a genetic pattern of the Chinese population in other countries. However, this association was still need to be confirmed by further studies. This result is important because children who are carrying a genetic mutation should modify their lifestyle to prevent obesity and its complication.

Other studies showed us that percentage of AA homozygote for the rs9939609 SNP of FTO was increased in children with obesity and a larger BMI increase in AA subjects compared with heterozygous subjects. $(18,21,27,29,30)$ Interestingly, our study has revealed difference results, frequency of AA homozygote for the rs9939609 FTO gene was lower in the case than in control group, and also lower when compared with TT genotype, but these results were similar to other studies in Malay and Chinese population. $(4,24)$ This different results could be explained related to the subjects' epigenetics due to different environments and lifestyle.

Some recent studies have found significant associations between FTO variants and obesity-related traits in AA adolescents and adults.(1,14,29-33) Children who have the AA genotype had a higher risk of obesity than the AA or TT genotypes, but others have found weaker, or non-significant associations in this race/ethnic group. $(24,34,35)$ Interestingly, homozygous subjects who have A-allele had a greater risk to develop obesity, whereas homozygous subjects with $\mathrm{T}$ allele might be protected from obesity.(14) 
In our study, we found an OR of 0.69 , means that AA genotype might be protected from weight gaining and children with TT genotype might be predisposed to develop obesity, but, more study is needed to ensure whether both alleles have two different functions, such as one predisposing and the other protective or one of the two alleles determines a gain or loss of function. These different results from different studies might be attributable to the differences in ethnic groups, sample sizes, physical activity, and environmental exposure.

We have several strengths in our study, i.e. this is the first study in Indonesia, the study population was a well-defined, homogenous group of children, and we used standardized methods to measure the clinical parameters, such as body height, weight, and waist circumference. Several limitations, however, are apparent, the respondents may not represent the whole Indonesian population, therefore, further studies were needed in other ethnic groups within the Indonesian population to investigate the possible gene-environment interaction that causes a different findings in different population. We evaluated only one polymorphism of FTO gene, which may be in linkage disequilibrium (26) with polymorphisms of other nearby genes that might have a contribution to the development of obesity.

Animal study provides direct evidence that FTO directly affects fat mass and thus is likely to have a role in human obesity.(36) Understanding the way the FTO variant affects fat mass, it can help us to understand the pathogenesis of obesity. The FTO variant may increase energy intake and diminishing satiety sensation therefore it contributes to weight gain. Mutation of FTO was influenced by higher intake of fatty acid. Previous findings have suggested that the regulation of food intake was influenced by FTO gene, therefore a child who carries the risk allele tend to choose higher energy and more fat food. $(37,38)$

Genetic influences are one of the probabilistic risk factors that must be considered together with environmental influences. Genetic influences may be driving environmental exposure, therefore throughout the life span an individual will be at risk for obesity.(39) Some chemicals in the form of environmental toxins are known to induce obesity, and the range of metabolic process and genes affected involve alteration to epigenetic patterns.(40) Other study showed important links between the FTO genetic predisposition for obesity and the development of obesity, it suggested that this genetic predisposition may be kept under control only if it is known in due time (neo-/postnatal) or if the lifestyle of the subjects includes high physical exercise and a constant diet.(41) However, we suggest further prospective studies to confirm the observed association and underlying mechanism to clarify the association between rs9939609 FTO gene with early onset obesity.

\section{Conclusion}

In conclusion, our results showed a significant association between FTO gene polymorphism with early onset obesity in Chinese ethnicity but not in Bataknese. The frequency of the AA homozygote was lower in early onset obesity than in control children, this study also showed that AA might be protected from gaining weight and TT may be predisposed to develop obesity.

\section{Acknowledgement}

We are grateful to the children who participated in our study, and to all field workers, data, and laboratory personnel.

\section{References}

1. Fang H, Li Y, Du S, Hu X, Zhang Q, Liu A, et al. Variant rs9939609 in the FTO gene is associated with body mass index among Chinese children. Med Genet. 2010; 11: 2-7.

2. Hubáček JA, Pikhart H, Peasey A, Kubinova R, Bobak M. FTO variant, energy intake, physical activity, and basal metabolic rate in Caucasians. The HAPIEE study. Physiol Res. 2011; 60: 175-83.

3. Xu S, Xue Y. Pediatric obesity: Causes, symptoms, prevention and treatment (Review). Exp Ther Med. 2016; 11: 15-20.

4. Yang M, Xu Y, Liang L, Fu J, Xiong F, Liu G, et al. The effects of genetic variation in FTO rs9939609 on obesity and dietary preferences in Chinese Han children and Adolescents. PLoS ONE. 2014; 9: 1-9. doi: 10.1371/journal.pone.0104574.

5. Hotta K, Nakata Y, Matsuo T, Kamohara S, Kotani K, Komatsu R, et $a l$. Variations in the FTO gene are associated with severe obesity in the Japanese. J Hum Genet. 2008; 53: 546-53.

6. Frayling TM, Timpson NJ, Weedon MN, Zeggini E, Freathy RM, Lindgren $\mathrm{CM}$, et al. A common variation in the FTO gene is associated with body mass index and predisposes to childhood and adult obesity. Science. 2007; 316: 889-94.

7. Karasawa S, Daimon M, Sasaki S, Toriyama S, Oizumi T, Susa S, et al. Association of the common fat mass and obesity associated (FTO) gene polymorphism with obesity in a Japanese population. Endocr J. 2010; 57: 293-301.

8. Lucky MH, Baig S, Zil-e-Rubab, Danish H, Ahmed F. Association of rs9939609 FTO gene variant with obesity among Karachi adolescent. EJBB. 2014; 2: 20-4.

9. Ursu RI, Badiu C, Cucu N, Ursu GF, Craciunescu I, Severin E, et $a l$. The study of the rs9939609 gene polymorphism in association with obesity and the management of obesity in a Romanian cohort J Med Life. 2015; 8: 232-8. 
10. Ogden CL, Flegal KM. Changes in terminology for childhood overweight and obesity. U.S Department of Health and Human Services, Centers for Disease Control and Prevention, National Center for Health Statistics. Natl Health Stat Report. 2010; 25: 1-8.

11. Peng S, Zhu Y, Xu F, Ren X, Li X, Lai M. FTO gene polymorphisms and obesity risk: A meta-analysis. BMC Med. 2011; 9: 71. doi: 10.1186/1741-7015-9-71.

12. Xi B, Shen Y, Zhang M, Liu X, Zhao X, Wu L, et al. The common rs9939609 variant of the fat mass and obesity-associated gene is associated with obesity risk in children and adolescents of Beijing, China. BMC Med Genet. 2010; 11: 107. doi: 10.1186/1471-235011-107.

13. Mačeková S, Bernasovský I, Gabriková D, Bôžiková A, Bernasovská $\mathrm{J}$, Boroňová I, et al. Association of the FTO rs9939609 polymorphism with obesity in Roma/Gypsy population. Am J Phys Anthropol. 2012; 147: 30-4.

14. Zavattari P, Loche A, Pilia S, Ibba A, Moi L, Guzzetti C, et al. rs9939609 in the FTO gene is associated with obesity but not with several biochemical parameters in Sardinian obese children. Ann Hum Genet. 2011; 75: 648-54.

15. Qi L, Kang K, Zhang C, van Dam RM, Kraft P, Hunter D, et al. Fat mass and obesity associated (FTO) gene variant is associated with obesity. Longitudinal analyses in two cohort studies and functional test. Diabetes. 2008; 57: 3145-51.

16. Xi B, Mi J. FTO polymorphisms are associated with obesity but not with diabetes in East Asian populations: A meta-analysis. Biomed Environ Sci. 2009; 22: 449-57.

17. Chang YC, Liu PH, Lee WJ, Chang TJ, Jiang YD, Li HY, et al. Common variation in the fat mass and obesity-associated (FTO) gene confers risk of obesity and modulates BMI in the Chinese population. Diabetes. 2008; 57: 2245-52.

18. Shinozaki K, Okuda M. The effects of fat mass and obesity-associated gene variants on the body mass index among ethnic groups and in children and adults. Indian J Endocrinol Metab. 2012; 16: S588-95.

19. Apalasamy YD, Ming MF, Rampal S, Bulgiba A, Mohamed Z. Genetic association of SNPs in the FTO gene and predisposition to obesity in Malaysian Malays. Braz J Med Biol Res. 2012; 45: 111926.

20. Garver WS. Gene-diet interactions in childhood obesity. Curr Genomics. 2011; 12: 180-9.

21. Rendo T, Moleres A, Moral AMD. Effects of the FTO gene on lifestyle intervention studies in children. Obes Facts. 2009; 2:393-9.

22. Gu HF, Alvarsson A, Brismar K. The common FTO genetic polymorphism rs9939609 is associated with increased BMI in type 1 diabetes but not with diabetic nephropathy. Biomark insights. 2010; 5: 29-32.

23. Shahid A, Rana S, Saeed S, Imran M, Afzal N, Mahmood S. Common variant of FTO gene, rs9939609, and obesity in Pakistani females. Biomed Res Int. 2013; 2013: 324093. doi: 10.1155/2013/324093.

24. Li H, Wu Y, Loos RJ, Hu FB, Liu Y, Wang J, et al. Variants in the fat mass- and obesity-associated (FTO) gene are not associated with obesity in a Chinese Han population. Diabetes. 2008; 57: 264-8.

25. Albuquerque D, Nóbrega C, Manco L. Association of FTO polymorphisms with obesity and obesity-related outcomes in Portuguese children. PLoS ONE. 2013; 8: e54370. doi: 10.1371/ journal.pone. 0054370 .

26. Hakanen M, Raitakari OT, Lehtimäki T, Peltonen N, Pahkala K, Sillanmäki L, et al. FTO Genotype Is Associated with Body Mass Index after the Age of Seven Years But Not with Energy Intake or
Leisure-Time Physical Activity. J Clin Endocrinol Metab. 2009; 94: 1281-7.

27. Tan JT, Dorajoo R, Seielstad M, Sim XL, Ong RT, Chia KS, et al. FTO variants are associated with obesity in the Chinese and Malay populations in Singapore. Diabetes. 2008; 57: 2851-7.

28. Chey WW, Fan SH, Say YH. Association of fat mass and obesity associated (FTO) gene rs9939609 variant with obesity among multi-ethnic Malaysians in Kampar, Perak. Sains Malaysiana. 2013; 42: 365-71.

29. Andreasen CH, Petersen KLS, Mogensen MS, Torekov SS, Wegner L, Andersen G, et al. Low physical activity accentuates the effect of the FTO rs9939609 polymorphism on body fat accumulation. Diabetes. 2008; 57: 95-101.

30. Woehning A, Schultz JH, Roeder E, Moeltner A, Isermann B, Nawrothet PP, et al. The A-allele of the common FTO gene variant rs9939609 complicates weight maintenance in severe obese patients. Int J Obes. 2013; 37: 135-9.

31. Cecil JE, Tavendale R, Watt P, Hetherington MM, Palmer CNA. An obesity-associated FTO gene variant and increased energy intake in children. N Engl J Med. 2008; 359: 2558-66.

32. Rutters F, Nieuwenhuizen AG, Bouwman F, Mariman E, WesterterpPlantenga MS, et al. Associations between a single nucleotide polymorphism of the FTO gene (rs9939609) and obesity-related characteristics over time during puberty in a Dutch Children Cohort. J Clin Endocrinol Metab. 2011; 96: E939-42.

33. Mangge H, Renner W, Alma G, Weghuber D, Möller R, Horejsi R. Rs9939609 variant of the fat mass and obesity-associated gene and trunk obesity in adolescents. J Obes. 2011: 186368. doi: 10.1155/2011/186368.

34. Hennig BJ, Fulford AJ, Sirugo G, Rayco-Solon P, Hattersley AT, Frayling TM, et al. FTO gene variation and measures of body mass in an African population. BMC Med Genet. 2009; 10: 21. doi: 10.1186/1471-2350-10-21.

35. Church C, Lee S, Bagg EAL, McTaggart JS, Deacon R, Gerken T, et al. A mouse model for the metabolic effects of the human fat mass and obesity associated FTO gene. PloS Genet. 2009; 5: e1000599. doi: 10.1371/journal.pgen.1000599.

36. Demerath EW, Lutsey PL, Monda KL, Linda Kao WH, Bressler J, Pankow JS, et al. Interaction of FTO and physical activity level on adiposity in African-American and European-American adults: The ARIC Study. Obesity. 2011; 19: 1866-72.

37. Liu C, Mou S, Chai Y. FTO Gene Variant and Risk of Overweight and Obesity among Children and Adolescents: a Systematic Review and Meta-Analysis. PLoS ONE. 2013; 8; e82133. doi: 10.1371/journal. pone.0082133.

38. Tanofsky-Kraff M, Han JC, Anandalingam K, Shomaker LB, Columbo KM, Wolkoff LE, et al. The FTO gene rs9939609 obesityrisk allele and loss of control over eating. Am J Clin Nutr. 2009; 90: 1483-8.

39. Haworth CMA, Carnell S, Meaburn EL, Davis OSP, Plomin R, Wardle J. Increasing heritability of BMI and stronger associations with the FTO gene over childhood. Obesity. 2008; 16: 2663-8.

40. Youngson NA, Morris MJ. What obesity research tells us about epigenetic mechanisms. Phil Trans R Soc Lond B Biol Sci. 2013; 368: 20110337. doi: 10.1098/rstb.2011.0337.

41. Ursu RI, Badiu C, Cucu N, Ursu GF, Craciunescu I, Severin E. The study of the rs9939609 FTO gene polymorphism in association with obesity and the management of obesity in a Romanian cohort. J Med Life. 2015; 8: 232-8. 